\title{
Liquid Biopsy in Liquid Tumors
}

\author{
Stella Maris Ranuncolo ${ }^{1,2,3}$ \\ ${ }^{1}$ Basic Science and Experimental Medicine Institute (ICBME), Academic Institute of the Italian Hospital (IU-HI), Buenos Aires, \\ Argentina \\ ${ }^{2}$ CONICET (National Scientific Research Council), Buenos Aires, Argentina \\ ${ }^{3}$ School of Medicine of the University of Buenos Aires (UBA), Buenos Aires, Argentina \\ Email: stella.ranuncolo@hospitalitaliano.org.ar
}

How to cite this paper: Ranuncolo, S.M. (2017) Liquid Biopsy in Liquid Tumors. Journal of Cancer Therapy, 8, 302-320. https://doi.org/10.4236/jct.2017.83026

Received: February 11, 2017

Accepted: March 28, 2017

Published: March 31, 2017

Copyright $\odot 2017$ by author and Scientific Research Publishing Inc. This work is licensed under the Creative Commons Attribution International License (CC BY 4.0).

http://creativecommons.org/licenses/by/4.0/

\begin{abstract}
The availability of a minimally invasive patient simple, capable of providing tumor information, represents a valuable clinical tool. The liquid biopsy has the potential to achieve this need. Circulating cell free DNA (ccfDNA), other circulating nucleic acids such as microRNA and circulating tumor cells (CTCs), can be obtained from a peripheral blood sample. Liquid biopsy has been particularly studied in solid tumors, specially of the epitelial origin, such as a pancreatic carcinoma and advanced breast cancer. It has been considerably less applied to the study of non-solid tumors. It represents an important source for diagnosis, prognosis and predictive information. Also it is suitable to evaluate response to therapy and drugs pharmacokinetics. It provides a unique opportunity to evaluate the disease evolution in serial blood samples collection, otherwise difficult to obtain. Liquid biopsy can be rehearsed using different circulating biological fluids such as whole blood, serum, plasma and lymph, as well as, non-circulating fluids such as urine, feces, saliva, bile and accumulated pathological fluids such as ascites. This review summarizes the current status of circulating material analysis in non-solid tunors. It is specially focused on Hodgkin Lymphoma and among Non-Hodgkin Lymphoma, it refers particularly to Diffuse Large B cell Lymphoma, the most common aggressive Non-Hodgkin Lymphoma derived from germinal center B-cells in adults. It further discusses the benefit of liquid biopsy in oncohemtaological diseases and potential clinical applications.
\end{abstract}

\section{Keywords}

Liquid Biopsy, Non-Hodgkin Lymphoma, Hodgkin Lymphoma, Circulating Tumor Cell (CTC), Circulating Cell Free DNA (ccfDNA)

\section{General Considerations}

Liquid biopsy represents a late development of an antique discovery. The first 
report on CTCs (Circulating Tumor Cells) was from 1869 when an Australian physician described a case in which cells, similar to those in the tumor, were seen in blood following patient's death [1]. This topic rested for a long time until Mandel and Métais found circulating nucleic acids in blood [2]. The 1945-1955 decade showed an increased interest in this field and many papers were published [3] [4]. It was during the 90's when different research groups went back to circulating DNA to analyze microsatellite alterations [5] [6] [7]. Over the last ten years, the detection and molecular characterization of CTCs, along with circulating cell free DNA (ccfDNA) analysis, have received enormous attention as new biomarkers and are currently a subject of both basic and clinical research [8].

\section{Circulating Tumor Cells (CTCs)}

The number of CTCs in the blood stream is considerably low. It is accepted that there might be $1 \mathrm{CTC} / 10^{9}$ cells in a patient blood sample with a metastatic tumor. The studies on CTCs are aimed to evaluate the risk of relapse in an oncological patient, to select treatment and monitor response to therapy, to identify novel therapeutic targets, to detect driver mutations that might be druggable if known, to evaluate pharmacodynamic effects, to analyze resistance mechanisms or to understand molecular basis of tumor metastasis dissemination [9] [10]. CTCs and ccfDNA, likely provide a mean of the intra-tumour heterogeneity of cancer, since this genetic circulating material may arise from all different tumor sections, being more representative that the information provided by a single tissue biopsy [10]. Although there is still no absolute consensus regarding the representativity of the information obtained from circulating genetic material studies and there is an urgent need for techniques standardization, a considerable advance has been made [11]. Furthermore, following the identification of a potential novel biomarker, it has to undergo a validation process, consisting of three stages: the analytical validation, the clinical validation and the clinical utility [12] [13] [14] [15] [16]. Other aspect to be considered is the fact that CTCs do not constitute a homogeneous cell popula-tion even when coming from the same tumor. In a carcinoma patient, some CTCs exhibit a defined epitelial phenotype, meanwhile other sub-population might show epithelial to mesenchymal transition characteristics [17].

Different methods, based on the physical and molecular CTCs features, have been recently developed and some of them have been enumerated in Table 1. Among the immunomagnetic assays, based upon positive CTCs selection, the Cell Search technology, developed by Janssen Diagnostics, is already approved for clinical use in metastatic breast cancer patients. A cut-off point of 5 CTCs detected in this group of patients showed prognosis value in terms of Disease Free Survival (DFS) and Overall Survival (OS). Patients with less than 5 CTCs per $7.5 \mathrm{ml} / \mathrm{blood}$ has a better prognosis. Also, among the immunomagnetic assays, but based on negative selection and close to be approved for clinical use, are the microfluidic chips named as CTC-Chip and CTC-iChip [18] [19] [20].

The first CTC-chip micro-spots array, containing antibody antiEpCAM(Epithelial Cell Adhesión Molecule), was initially used with metastatic 
Table 1. Methods to isolate circulating tumor cells. Different methods have been tried to improve the isolation of the very low percentage of circulating tumor cells in plasma, serum or whole blood simple.

\begin{tabular}{|c|c|c|}
\hline Method & Developer & Antibodies \\
\hline \multicolumn{3}{|c|}{ Immunomagnetic assays: Positive Selection } \\
\hline Cell Search & Janssen Diagnostics & EpCAM-coated beads \\
\hline Adna Test & $\begin{array}{c}\text { AdnaGen } \\
\text { (Langenhagen, Germany) }\end{array}$ & $\begin{array}{l}\text { EpCAM, MUC-1 Mesothelin, } \\
\text { molecular profiling }\end{array}$ \\
\hline $\begin{array}{c}\text { MACS Cell } \\
\text { Separation technology }\end{array}$ & $\begin{array}{c}\text { Miltenyi Bioteh } \\
\text { (BergischGLadbach, Germany) }\end{array}$ & EpCAM, pan-CK \\
\hline Dynabeads & Life Technologies & Monoclonal antibody BerEP4 \\
\hline Cell Collector & Gilupi & $\begin{array}{l}\text { Medical wire anti-EpCAM } \\
\text { coated placed into the patient vein } \\
\text { blood steam for } 30 \text { minutes. }\end{array}$ \\
\hline $\begin{array}{l}\text { Biofluidic CTC } \\
\text { Detection System }\end{array}$ & Biofluidica & EpCAM coated Chip \\
\hline \multicolumn{3}{|c|}{ Immunomagnetic assays: Negative Selection } \\
\hline $\begin{array}{l}\text { CTC-Chip } \\
\text { CTC-iChip }\end{array}$ & $\begin{array}{l}\text { Daniel Haber and Mehmer } \\
\text { Toner at Dana-Farber and } \\
\text { Massachusetts General Hospital }\end{array}$ & $\begin{array}{c}\text { EpCAM and } \\
\text { CD45/citokeratin substraction }\end{array}$ \\
\hline \multicolumn{3}{|c|}{ Based on CTCs biological and molecular features } \\
\hline \multicolumn{3}{|c|}{ Size } \\
\hline \multicolumn{3}{|c|}{ Size and deformability } \\
\hline \multicolumn{3}{|c|}{ Density } \\
\hline \multicolumn{3}{|c|}{ Physical properties } \\
\hline & Others & \\
\hline
\end{tabular}

Different methods have been tried to improve the isolation of the very low percentage of circulating tumor cells in plasma, serum or whole blood simple.

tumors including Non-Small Cell Lung Cancer (NSCLC), pancreatic cancer, breast carci- noma, colon cancer, localized and metastatic prostate carinoma and healthy do- nors. The number of CTCs/ml isolated was in average 155,16 to 292 , 25 to 174,9 to 831,5 to 176,42 to 375 and 0 respectively [20]. This technology relies on the cell surface expression of EpCAM, using antibody anti Ep-CAM coated beads. Consequently, this restrictes the method to the identification of carcinoma cells, leaving out tumors that arise from non-epithelial tissues.

Vimentin is usually consider a mesenchymal cell lineage marker. It has been reported that cell surface vimentin, can be used as an universal marker to identify CTCs from metastatic sarcomas, using a monoclonal antibody. This antibody was proven to be specific for vimentin bound to cancer cell surface. It did not show any binding toward macrophages, endothelial cells, neutrophils, platelets or apoptotic T lymphocytes [21].

\section{Circulating Cell Free DNA (ccfDNA)}

Extracellular DNA embraces both nuclear and mitocondrial DNA released from cells. This genetic material can be found in circulating fluids (whole blood, plas- 
ma, serum, lymph) non-circulating extracellular products (bile, milk, feces, urine, saliva, mucous suspension, spinal fluid, amniotic fluid) and liquid accumulated during certain pathological conditions (ascites, among others). Extracellular DNA molecules are found in humans, and both the animal and plant kingdoms. Also, extracellular DNA, can be isolated from the supernatant of tissue cultures [22].

The cirulating cell free DNA (ccfDNA) does not come from circulating cancer cells, considering the low number of CTCs and the amount of ccfDNA. We all have ccfDNA in physiological conditions, coming from tissues with a high cellular turn over rate, such as the bone marrow, the intestinal epithelium or the fetus during pregnancy. The mean ccfDNA concentration in healthy individuals is $2-5 \mathrm{ng} / \mathrm{ml}$. An enhanced amount can be isolate from individuals with chronic inflammatory diseases. Even higher, is the ccfDNA level in patients with cancer, ranging from 10 to $1000 \mathrm{ng} / \mathrm{ml}$. Only a low percentage of the total amount of ccfDNA corresponds to tumor cells. Circulating tumor DNA (ctDNA) has biochemical and biophysical different properties as compared to ccfDNA arising from non-tumor cells, such as the double strand fragments being less stable and bearing a different GCcomposition [23]. Tumor cells dying by apoptosis, necrosis, necroptosis, all processes in which DNA is fragmented, eject their nucleic acid into the blood stream. The ccfDNA can also originate by oncosis, phagocytosis and active secretion. This active secretion constitutes a striking mechanism by which eukaryotic cells release the so call virtosomes to circulation. Virtosomes are newly synthesized DNA/RNA/lipoprotein complexes found in the citosol. These complexes once released, can enter other cells, modifying the recipient cell biology even leading to its transformation, if the virtosome has originated from a cancer cell [24] [25]. DNA has the ability to complex with other molecules thus, it can be found associated with lipids and proteins as well as associated to membranes, from which it can detach and freed in the circulatory system, finally it can also be internalized in vesicles [26] [27] [28]. ccfDNA comprises double strand DNA fragments with less than 200 length. This ccfDNA has a short half-life suggesting an ongoing release event and further degradation [22]. These fragments size is close to the size of nucleosomes (146 bp) and chromatosomes (167 bp). It is believed that part of the circulating DNA could be represented by these two structures [29] [30].

It has been stablished that nucleosomes positioning varies among different cell types [31] [32]. Snyder, M.W. et al., investigated the transcription factors occupancy of nucleosomes in vivo, by deep sequencing of healthy donors plasma ccfDNA [33]. The analysis of these nucleosomes revealed the epigenetic features of myeloid and lymphoid cells indicating that in those healthy individuals, most of the plasma ccfDNA, comes from the turn over of bone marrow cells. In this sense, they suggest that such a nucleosome footprint could be applied to infer tissue origin of the ccfDNA [33]. In summary, there are two overwhelming functional aspects of ccfDNA, the capacity to behave as an intercellular messenger and the genometastasis [26] [27].

There are different approaches to characterize this ccfDNA such as PCR-based techniques, digital droplet PCR and BEAMing (all of them aimed to assess muta- 
tions and fusion genes previously known) and massively parallel sequencing with distinct sensitivity (focused on the novo genetic alterations discovery) [34].

\section{Other Circulating Material}

Beyond DNA, RNA and CTCs, other material can be also obtained from blood, among them we found microvesicles, exosomes, ectosomes and apoptotic bodies. Regarding blood ccfDNA, it has to be considered the neutrophils and eosinophils DNA traps, circulating DNA linked with serum proteins and cell membrane surface [35].

Exosomes originate from the membrane invagination of a subset of late endosomes, which ends up containing a large number of small vesicles, taking the name of multivesicular bodies. Exosomes are characterized by small dimensions (30 $100 \mathrm{~nm}$ ) and round shape. Instead, microvesicles bud from the plasma membrane and are characterized by a wider size (from $100 \mathrm{~nm}$ to $1000 \mathrm{~nm}$ ) and less regular morphology [36]. All cells generate exosomes but for still unknown reasons, malignant tumor cells release exosomes at a higher rate. Exosomes contain RNA, small and large non-coding RNAs, lipids, proteins and small amounts of DNA. This exosome DNA is found in two different localizations, larger doublestranded DNA fragments associated to the exosome external surface and shorter double-stranded DNA in its interior. These vesicles are currently undestood as a new intercellular communication mechanism and they are even capable of inducing transformation in recipient cells [35] [36] [37] [38].

Although extensive data related to liquid biopsy has been lately generated, there is still lack of consensus and applied asssays standardization, to reproduce results. Also, it seems necessary to design protocols including larger number of patients. Liquid biopsy has been extensively explored in patients with solid tumors, that is not being reviewed herein. Its potential benefits have been less evaluated in non-solid tumors and among these, the least investigation, has been performed in pediatric oncohematological pathologies. A summary of the clinical evidence based utility, for the distinct circulating elements performance as potential biomarkers, provided by liquid biopsy, can be found in Table 2 .

\section{Liquid Bipsy in Non-Solid Tumors}

As in solid tumor patients, non-solid oncopathology patients show higher ccfDNA as compared with healthy subjects. A 2009 screening in both Hodgkin (HL) and Non-Hodgkin Lymphoma (NHL) patients found that they had a ccfDNA median concentration of $24.1 \mathrm{ng} / \mathrm{ml}$ at diagnosis, which doubled the healthy control group ccfDNA median concentration. After two-years of follow up, $88 \%$ of NHL and $95 \%$ of HL patients, who developed complete response to therapy, showed a significant decrease in ccfDNA levels. ccfDNA at diagnosis correlated with serum lactate dehidrogenase (LDH) levels, tumor burden and prognosis, in terms of DFS [39]. LDH levels and tumor burden are two of the five parameters considered to determine the IPI (International Prognostic Index). The IPI is a clinical tool that aids in agressive NHL prognosis prediction, stratifying this group 
Table 2. Circulating biomarkers utility base on clinical evidence. Biomarkers potential suitable applications base on clincial evidence. Level I: well designed, randomized and controlled studies. Level II-1: well designed, contolled but non randomized studies. Level II-2: analytical studies with control cases, participation of more tan one center or group. Level III: Opinion of authorities in the field base on clinical experience and experts committees reports.

\begin{tabular}{|c|c|c|c|}
\hline & Nucleic Acid Type & Clinical application & Evidence level \\
\hline CTCs & & Prognosis & $\begin{array}{c}\text { I Metastatic } \\
\text { Breast Cancer } \\
\text { II-2 Prostate carcinoma }\end{array}$ \\
\hline Exosomes & & Prognosis & III \\
\hline \multirow[t]{3}{*}{$\begin{array}{c}\text { Circulating } \\
\text { Nucleic Acids }\end{array}$} & cfDNA & Prognosis & II-2 \\
\hline & cfRNA & Therapy response & III \\
\hline & miRNA & Prognosis & Pre-clinical \\
\hline
\end{tabular}

US preventative services task force.

of patients into low, intermediate-low, intermediate-high and high risk [40].

\subsection{Non-Hodgkin Lymphomas (NHL)}

\section{Diffuse Large B Cell Lymphoma (DLBCL)}

$B$ cell Non-Hodgkin Lymphoma comprises a wide range of genetically, phenotipically and clinically distinct lymphomas. Diffuse Large B Cell Lymphoma (DLBCL), Burkitt (BL) and Follicular Lymphomas (FL), account for approximatelly $80 \%$ of all NHL, being DLBCL the most frequent in adults [41].

Recently, liquid biopsy has been proven as an excellent source to genotyping DLBCL, in real time. Also it showed to be as accurately as doing it in a conventional biopsy. Furthermore, liquid biopsy has allowed to follow up the lymphoma evolution and patient response to treatment, in a non invasive manner plus, uncovering novel genetic alterations. This last achievement, overcomes the heterogeneity of this B-cell lymphoma. Ultra-deep next generation sequencing of plasma ccfDNA, in newly diagnosed DLBCL patients before treatment, showed the known mutations associated with this lymphoid disease. It was also feasible to uncover in ccfDNA, mutations that were detected during a conventional biopsy, due to the intrinsic heterogeneity of this B-cell lymphoma. Patients that responded to the R-CHOP treatment scheme, showed clearence of the alterations found in the diagnosis sample. On the other hand, resistant R-CHOP patients, remained harboring the same mutations meanwhile acquaring new ones, as a result of resistant clone selection. Camus, V. et al., developed digital PCR assays for the detection of recurrent mutations in ccfDNA DLBCL patients, focusing on those ones that woud allow patients to benefit from an available targeted therapy such as EZH2 and MYD88 mutations [42].

CCND2 and MYC mRNA levels were found in $14 \%$ and $10 \%$ respectively, in a study that included 42 DLBCL patients, and they correlated with worst prognosis in terms of shorter OS. Others mRNA levels also studied were BCL2, LMO2 
and BCL6, which were found in a less percentage of patients in the studied cohort, and no association was found with OS. None of them were associated with DFS [43]. To highlight is the fact that among the low risk DLBCL patients $(n=28)$ according to the IPI, those with CCND2 and MYC plasma mRNA had a shorter OS. Plasma mRNA could be useful to identify patients with poor prognosis in a subset of patients clinically classified as low risk [43].

Roschewski M. et al., show that ctDNA is reliable to monitor disease status in DLBCL patients. They demonstrated a positive association between ctDNA and disease progression. They studied a group of 107 DLBCL patients who achieved complete remission at the end of treatment. Overall, 17 patients relapsed, during the follow-up and 16 of them developed detectable ccfDNA before clinical evidence of disease progression [44].

Relapse in DLBCL patients, most likely is due to the persistance of minimal residue disease (MRD), bellow the detection of imaging. The possibility of analizing circulating material would largely improve this current situation.

Central Nervous System (CNS) relapse remains as an important issue in DLBCL patients. This needs better understanding in order to identify the subgroup of patients at high risk, so that they require effective targetting of CNS prophylaxis. This could be one of the clinical unsolved situations to explore in liquid biopsy since no biomarkers are available.

So far, it is known that patients with very aggressive lymhomas such as BL or Lymphoblastyc Limphomas, have to routinely receive CNS prophylaxis due to high relapse rate, meanwhile patients with indolent lymphomas, such as Marginal Lymphoma or FL, do not need it. However, it remains controversial whether DLBCL patients, the most common germinal center (GC) derived B Cell lymphoma in adults, shoud receive CNS prophylaxis. The research on this topic is extensive but still unconclusive [45]-[50].

CXCR4, CXCR5, CCR7, CXCL12, and CXCL13 expression have been evaluated by inmunohistochemistry on 89 tissue samples of patients with CNS primary and secondary lymphomas, as well as systemic DLBCL patients, in order to analyze lymphocytes CNS tropism. Interestingly, strong nuclear CXCR4 positivity correlated with systemic DLBCL, whereas strong cytoplasmic CXCR5 positivity, correlated with CNS involvement [51].

Regarding other complications, neutropenic fever is common in hematological patients, as a consecuense of aggressive chemotherapy schemes. Furthermore, these patients can take a course for the worst, developing serious infections such as sepsis. A study that included 100 oncohematological patients, showed that ccfDNA levels measurements did not predict late complications in patients with neutropenic fever, such as sepsis or septic shock. Interestingly, if hematological malignancies subgroups were analyzed, differences became more apparent. Acute Myeloid Leukemia (AML) patients had lower ccfDNA levels than lymphoma ones. The ratio ccfDNA/leucocytes among these two groups of patients, successfully identified those ones that would develop sepsis or septic shock. This promising result deserves deeper investigation [52]. The identification of biomarkers that 
could be determine in a blood sample by liquid biopsy, would represent an excellent resource to identify the sub-group of patients at enhanced risk of developing the above referred complications.

As referred before, while circulating genetic material has been widely investigated in patients with solid tumors, there are few reports on liquid or non-solid tumors. Among the non-solid tumors, there has been particularly less focus on the ccfDNA evaluation, in pediatric oncohematological diseases. Machado et al., studied total ccfDNA and EVB plasma DNA in 30 pediatric B cell NHLs. That group concluded that the analysis of ccfDNA could be useful for disease detection in pediatric EVB-associated lymphomas [53]. Regarding its prognosis value, it was later reported that the evaluation of minimal disseminated disease (MDD) was predictive of high risk of treatment failure, in pediatric Burkitt and Anaplastic Large Cell Lymphomas (ALCL) [54] [55] [56] [57].

Mussolin, L. et al., studied ccfDNA in plasma of 201 italian cases of pediatric lymphomas (43 cases of HL, 45 of ALCL, 88 BL, 17 lymphoblastic and 8 DLB$\mathrm{CL}$ ). The median ccfDNA was $1.6 \mathrm{ng} / \mathrm{ml}$ in the healthy control group and 46 $\mathrm{ng} / \mathrm{ml}$ in the lymphoma group of patients applying a real-time quantitative PCR for the POLR2 gene [58]. This is a repetitive finding both in liquid and solid oncology patients. As an example in solid tumors, Dr. Thierry's group, reported a median of $24.37 \mathrm{ng} / \mathrm{ml}$ of plasma ccfDNA in a group of 229 colorectal carcinoma patients versus a median concentration of $4.76 \mathrm{ng} / \mathrm{ml}$ in a group of 109 healthy individuals analyzed [59].

Interestingly, the group of Mussolin et al., found that the fraction of tumor DNA was higher in patients that had lower amount of total ccfDNA. Although BL patients showed the highest level of total ccfDNA, no association was found between plasma circulating DNA and lymphoma histoloy, B-symptoms, LDH levels, bulky disease or MDD. The 3-years follow-up period showed that total level of ccfDNA at diagnosis, had prognosis value in terms of DFS, since it was shorter in the group of patients that had a ccfDNA concentration over $46 \mathrm{ng} / \mathrm{ml}$ [58].

Somatically mutated inmunoglobulin genes represent an unique marker for GC derived B cell lymphomas [60] [61].

Immunoglobulin genes high-throughput sequencing, particularly the $\mathrm{D}(\mathrm{Di}$ versity) and J (Joining) genes joint, provides a unique DNA clonotype shared by all malignant B cells. This method has been used for diverse B cell malignancies including DLBCL cases [47] [62] [63]. In this regard, Kurtz, D.M. et al., analyzed 311 blood samples corresponding to 75 DLBCL patients. They explored the clinical utility of immunoglobulin genes sequencing, for detection of molecular disease from plasma DNA and peripheral blood CTCs, for disease monitoring compared to PET/CT and clinical outcome [62]. So far, including this paper, clonotypic sequences identified in ctDNA and CTCs, has to be compared to the sequences found in fresh or frozen tissue samples from the same patient. This group observed, as it was concluded from many other studies, that they could isolate a larger amount of tumor DNA from plasma and with higher quality, as 
compared with DNA obtained from CTCs. Also, ctDNA levels showed a better positive correlation with the tumor volume as measured by PET/CT scan. These findings led to think that plasma ccfDNA might be both more sensitive and accurately, reflecting disease burden, as compared with results obtained using DNA isolated from CTCs.

Most of the studies published on liquid biopsy have isolated ccfDNA from plasma. It has been reported that it seems more convenient to obtain circulating DNA from plasma as compared with serum (Table 3 ). In general terms, it is also more easy, to perform the type of analysis that liquid biopsy intends to, on ccfDNA as compared to CTCs (Table 4).

DLBCL, a heterogeneous B-cell malignancy, has been classified in two main molecular subtypes according to gene expression profile: ABC-Like (Activated $\mathrm{B}$ Cell) and GCB-Like (Germinal Center B cell) based on the cell of origin [64]. ccfDNA somatic mutations detected by Next Generation Sequencing (NGS), successfully reflect genetic features that distinguish both subtypes. They analyzed mutations in ctDNA and tissue. The single nucleotide variants were identified in genes that defined ABC-Like (MYD88, CD79A/B, PRDM1, CARD 11, IRF4) and GCBLike (EZH2, BCL2, GNA13, TNFSRF14) DLBCL subtypes [65]. It was possible to quantify MRD in plasma ccfDNA in DLBCL and Primary Mediastinal B-Cell Lymphoma (PMBL) patients. They used a high-throughput sequencing method named as LymphoSIGHT.

All these reports even though, they have been usually performed in a small number of patients, are promising, specially considering that it is believed that

Table 3. Advantages and disadvantages of ccfDNA isolated from serum and plasma. Circulating cell free DNA with higher quality, purity and sensibility of detection, is isolated from plasma as compared to serum samples.

\begin{tabular}{ccc}
\hline ccfDNA & Serum & Plasma \\
\hline Quantity & $>$ & $>$ \\
Quality & $<$ & $>$ \\
Purity & $<$ & $>$ \\
Detection sensibility & $<$ & \\
\hline
\end{tabular}

Table 4. Differences betwen CTCs and ccfDNA isolation. The process and methodology to isolate ccfDNA is easier, as compared to the ones needed to isolate CTCs.

\begin{tabular}{ccc}
\hline & CTCs & ccfDNA \\
\hline Equipment & Need of specializad equipment & No need \\
Isolation & Complex & Standard DNA preparation \\
Whole Genome Amplication & Yes & No \\
Heterogeneity & yes & Results represent an average \\
Specific markers for isolation & Dependent & No dependent \\
MTS & Ideal material & No \\
Diagnosis and monitoring & Stablished by clinical studies & Clinical studies pending
\end{tabular}


only a few DLBCL patients have evidence of circulating disease [66] [67] [68] [69] [70].

Epigenetic modifications have also been explored in liquid biopsy as potential DLBCL biomarkers. DAPK1, DBC1, MIR34A, and MIR34B/C promoters aberrant methylation, determined by pyrosequencing, was identified in plasma ccfDNA of DLBCL patients at diagnosis. During R-CHOP treatment, patients that were sensitive and responsive, lost of DAPK1 promoter hypermethylation occured. On the other side, patients that did not respond, mantained or regained promoters aberrant methylation and had a poor prognosis, in terms of OS [71]. Aberrant methylation in DLBCL ccfDNA patients seems to be an independent prognosis biomarker also suitable to assess response to therapy [71].

\subsection{Hodgkin Lymphoma (HL)}

Hodgkin Lymphoma (HL) is one of the most common B cell lymphoma derived from the GC. Nowadays, all these patients are treated with the same chemotherapy schedule, which combines four citotoxic drugs. Chemosensitive patients could even reach the cure. Nevertheless, the probability of relapse is $10 \%$, and commonly take place during the first twelve months following diagnose.

The initially refractory patients, despite different rescue stratagies, remain unresponsive although improvements in adjuvant therapy (conjugated monoclonal antibodies plus high chemotherapy and autologous bone marrow transplant), have been made [72] [73] [74]. If we add the fact that most of these patients are young adults, with high risk of developing cardiovascular and respiratory complications as well as other tumors and sterility, it is largely justified the screen for predictive biomarkers capable of identifying such sub-group of patients at diagnosis. Liquid biopsy could represent an useful tool to perform this.

In this regard it has been reported that, the E571K Exportin 1 (XPO1) mutation assessed by digital PCR in ccfDNA, could have prognosis value in $\mathrm{CHL}$ (classical Hodgkin Lymphoma) patients. The four histological subtypes of cHL account for the $95 \%$ of patients diagnosed with HL. The presence of this XPO1 mutation in plasma DNA cHL patients after treatment, correlated with shorter DFS [75].

It has been investigated the role of cell free circulating microRNAs (ccfmicroRNA) in cHL patient plasma. Higher levels of ccfmiR-494, miR-1973 and miR21 , were detected in cHL patients as compared to healthy subjects. Levels of these three microRNAs decreased when patients developed a complete response to chemotherapy. Only fluctions of miR-494 and miR-1973 levels, reflected response during therapy, with reduction being more pronunce in patients achiving complete versus partial response [76].

Novel and interesting results were obtained applying a standardized size-exclusion chromatography method, to isolate vesicle microRNA from plasma cHL patients. Sequenced RNA candidates were validated by quantitative RT-PCR. The isolated vesicles from plasma HL patients at diagnosis before treatment were enriched for miR-24-3p, miR-127-3p, miR-21-5p, miR-155-5p and let7a-5p as 
compared to vesicles isolated from healthy controls. Those vesicles microRNAs levels significantly decreced or even disappeared after treatment in patients that developed complete response. If a responsive patient later relapsed, this was accompanied by an enhanced microRNA level. Remarkably, there was a correlation between plasma circulating microRNAs and the patient status, determined by the fluorodeoxyglucose-PET before, during and once treatment was completed [77].

The evaluation of a large cohort of pediatric HL patients, showed higher ccfDNA levels as compared to controls. The follow-up showed that an enhancement in ccfDNA after treatment correlated with worse prognosis [78].

\subsection{Other Liquid Tumors}

This review has specially focused on Hodgkin and Non-Hodgkin Lymphomas, since other hematological diseases including leukemias and multiple mieloma (MM), have been less prominent as a subject of diagnostic, prognostic or predictive biomarkers screening in liquid biopsy.

Extracellular vesicle microRNA-155 has been analyzed as a potential diagnostic biomarker in several different hematological malignancies. The extracellular vesicles were isolated by differential centrifugation and its quality verified by atomic force and transmission electron microscopy. The microRNA was analyzed by quantitative RT-PCR. High microRNA-155 levels were detected in acute myeloid leukemia (AML), chronic lymphocytic leukemia (CLL) and Waldenstrom's Macroglobulinemia (WM) as compared to the group of healthy controls. microRNA-155 levels were significantly lower in multiple mieloma (MM), BL, FL and DLBCL [79].

$\mathrm{N}$-ras point mutations have been determined by PCR in plasma ccfDNA, peripheral blood cells and bone marrow samples of acute myelogenous leukemia patients (AML). The study showed that the spectrum of alterations determined in plasma ccfDNA was wider as compared to the finding observed in the bone marrow samples [80]. More recently a microRNA signature, including miR199b-5p, miR-301b, miR-326, miR-361-5p, miR-625 and miR-655 was analyzed in AML plasma patients before and after chemotherapy. It was observed that the high microRNAs levels decreased following response to therapy [81].

Similar to the results obtained from ccfDNA in AML patients, the analysis of mutations in paired ccfDNA and bone marrow biopsy DNA in MM patients, showed that more information is obtained from the first sample. NRAS, KRAS, BRAF and p53 mutations were analyzed in newly diagnosed and relapsed/ refractory MM patients showing higher frequency of mutations in the first group of patients. They observed that activating RAS mutation, was higly prevalent in MM patients, as it has been previously described. This work showed that ccfDNA analysis improved the mutational pattern characterization in MM patients as well as allowed monitoring response to therapy [82].

In a recently published pilot study, the myeloma VDJ rearrangement was investigated by next generation sequencing in ccfDNA and circulating myeloma 
cells. Therapy responder patients, evidenced a prompt clearence of the VDJ myeloma rearrangement, meanwhile it persisted in refractory patients after treatment [83].

Long non-coding RNAs (lncRNA), are the least circulating nucleic acids, investigasted as potential biomarkers in cancer; including both solid and nonsolid tumors. In any case, further studies are necessary to elucídate their role in oncopathology.

A study of plasma lncRNAs, including TUG1, LincRNA-p21, MALAT1, HOTAR and GAS5 by real-time PCR, in Chronic Lymphocytic Leukemia (CLL) and MM patients was carried out. It was only observed significantly higher LincRNA-p21 levels in the CLL group of patients as compared to healthy control individuals. Regarding MM patients, they found an enhanced TUG1 level [84].

Liquid biopsy present the unique opportunity to examine th disease biology at diagnosis and to monitor the disease as it evolves over time, minimizing patient discomfort. There is a deep need of moving forward after the biomarker discovery, to the description of its performance including the device that is used, the assay that is being carried out, the software applied for results analysis and the range of conditions under which the measurement gives reproducible and accurate results. Then, there should be trials from phase 1 to phase 3, designed to demonstrate that the candidate biomarker is "fit for the purpose", for a specific context of use. To start it is necessary to examine the frequency at which the biomarker is present in the illness for which is considered a candidate and the group of patients that migh potentially benefit from its determination. Lastly, it has to be showed that the test result, has an impact on the patient management and therapecutic secheme selection.

Liquid biopsy promises to contribute better to patient prognosis, both before and after treatment, as compared to diagnosis. Despite the terrific technological advancement, the analytical validation, clinical validation and clinical utility for the ccfDNA and CTCs analysis methods need to be standardized.

The study of tumor genetic alterations has traditionally been performed on tissue biopsy material. However, many tumors are difficult to biopsy, for various reasons. Tumor localization could be accessible only using fine needle aspirates, obtaining as a consequence a quite small sample of usable material, just enough to approch a diagnosis. In this context it might be difficult ore ven imposible to move forward to molecular analysis. Also, tumors can be located either in unknown sites. There is a $10 \%$ of patients in whom, the onset of the oncology disease, occurs with metastatic lesions in multiple sites bearing an unknown primary tumor. Evenmore, the tumor couls be located in challenging and risky sited to be successfully accessed such as it occurs in CNS. The traditional methods for genetic alterations tumor assessment, fail to capture the heterogeneity of the disease, especially during its progression. The Liquid Biopsy can profoundly improve the way clinicians face and respond to these issues. The Liquid biopsy, with a simple blood drawn, can simultaneously sample different sites compromised by the disease or distinct primary tumor sections, finally 
building a "fluid" picture of the tumor cell alterations. Liquid biopsy can be repeated as needed, specially for effective monitoring of the disease evolution and the patient response to therapy. As a detailed picture of the mutations that drive oncogenesis emerges, new avenues for researchers, clinicians, and drug developers are currently being opened up.

\section{References}

[1] Ashworth, T.R. (1869) A Case of Cancer in Which Cells Similar to Those in the Tumours Were Seen in the Blood after Death. The Medical Journal of Australia, 14, 146-147.

[2] Mandel, P. and Métais, P. (1948) Les acides nucléiques du plasma sanguin chez l'Homme. Comptes Rendus des Seances de la Societe de Biologie et de ses Filiales, 142, 241-243.

[3] Engell, H.C. (1955) Cancer Cells in the Circulating Blood: A Clinical Study on the Occurrence of Cancer Cells in the Peripheral Blood an in Venous Blood Draining the Tumor Area at Operation. Acta chirurgica Scandinavica Supplementum, 201, 170 .

[4] Christopherson, W. (1965) Cancer Cells in the Peripheral Blood: A Second Look. Acta Cytologica, 9, 169-174.

[5] Goessl, C., Heicappell, R., Münker, R., Anker, P., Stroun, M., Krause, H., Müller, M. and Miller, K. (1998) Microsatellite Analysis of Plasma DNA from Patients with Clear Cell Renal Carcinoma. Cancer Research, 58, 4728-4732.

[6] Nawroz, H., Koch, W., Anker, P., Stroun, M. and Sidransky, D. (1996) Microsatellite Alterations in Serum DNA of Head and Neck Cancer Patients. Nature Medicine, 2, 1035-1037. https://doi.org/10.1038/nm0996-1035

[7] Chen, X.Q., Stroun, M., Magnenat, J.L., Nicod, L.P., Kurt, A.M., Lyautey, J., Lederrey, C. and Anker, P. (1996) Microsatellite Alterations in Plasma DNA of Small Cell Lung Cancer Patients. Nature Medicine, 2, 1033-1035. https://doi.org/10.1038/nm0996-1033

[8] Ranuncolo, S.M. (2016) Towards the Dreamed Biomarkers? Journal of Molecular Biomarkers \& Diagnosis, S2, e002.

[9] Alix-Panabières, C. and Pantel, K. (2013) Circulating Tumor Cells: Liquid Biopsy of Cancer. Clinical Chemistry, 59, 110-118.

[10] De Mattos-Arruda, L., Cortes, J., Santarpia, I., Vivancos, A., Tabernero, J., Reis, J.S., et al. (2013) Circulating Tumour Cells and Cell-Free DNA as Tools for Managing Breast Cancer. Nature Reviews Clinical Oncology, 10, 377-389. https://doi.org/10.1038/nrclinonc.2013.80

[11] Crowley, E., Di Nicolantonio, F., Loupakis, F. and Bardelli, A. (2013) Liquid Biopsy: Monitoring Cancer Genetics in the Blood. Nature Reviews Clinical Oncology, 10, 472-484. https://doi.org/10.1038/nrclinonc.2013.110

[12] Scher, H.L., Moris, M.J., Larson, S. and Heller, G. (2013) Validation and Clinical Utility of Prostate Cancer Biomarkers. Nature Reviews Clinical Oncology, 10, 225 234. https://doi.org/10.1038/nrclinonc.2013.30

[13] Woodcock, J. and Woosley, R. (2008) The FDA Critical Pathway Initiative and Its Influence on New Drug Development. Annu. Rev. Med., 59, 1-12.

https://www.c-path.org/pdf/FDAcriticalpathinitiativeinfluenceonnewdrugdevelopm entWoodcockWoosley.pdf

[14] Hayes, D.F., Allen, J., Compton, C., Gustavsen, G., Leonard, D.G., McCormack, R., et al. (2013) Breaking a Vicious Cycle. Science Translational Medicine, 5, $196 \mathrm{~cm} 6$. 
https://doi.org/10.1126/scitranslmed.3005950

[15] Center for Drug Evaluation and Research (CDER), Food \& Drug Administration, United States Department of Health and Human Services (2011) Guidance for Industry: E16 Biomarkers Related to Drugs or Biotechnology Product Development: Context, Structure and Format of Quantification Submissions.

[16] Michael, C. and Ball, J. (2010) Institute of Medicine (U.S.) Committee on Qualifications of Biomarkers and Surrogate Endpoints in Chronic Disease. Evaluation of Biomarkers and Surrogate Endpointsin Chronic Disease. National Academic Press, Washington DC, 314.

[17] Parkinson, D.R., Dracopoli, N., Petty, B.G., Compton, C., Cristofanilli, M., Deisseroth, A., et al. (2012) Considerations in the Development of Cirsulting Tumor Cell Technology for Clinical Use. Journal of Translational Medicine, 10, 138. https://doi.org/10.1186/1479-5876-10-138

[18] Karabacak, N.M., Spuhler, P.S., Fachin, F., Lim, E.J., Pai, V., Ozkumur, E., Martel, J.M., Kojic, N., Smith, K., Chen, P., Yang, J., Hwang, H., Morgan, B., Trautwein, J., Barber, T.A., Stott, S.L., Maheswaran, S., Kapur, R., Haber, D.A. and Toner, M. (2014) Microfluidic, Marker-Free Isolation of Circulating Tumor Cells from Blood Samples. Nature Protocols, 9, 694-710. https://doi.org/10.1038/nprot.2014.044

[19] Yap, T.A., Lorente, D., Omlin, A., Olmos, D. and de Bono, J.S. (2007) Circulating Tumor Cells: A Multifunctional Biomarker. Clinical Cancer Research, 20, $2553-$ 2568. https://doi.org/10.1158/1078-0432.CCR-13-2664

[20] Nagrath, S., Sequist, L.V., Maheswaran, S., Bell, D.W., Irimia, D., Ulkus, L., Smith, M.R., Kwak, E.L., Digumarthy, S., Muzikansky, A., Ryan, P., Bails, U.J., Tompkins, R.G., Haber, D.A. and Toner, M. (2007) Isolation of Rare Circulating Tumour Cells in Cancer Patients by Microchip Technology. Nature, 450, 1235-1239. https://doi.org/10.1038/nature06385

[21] Satelli, A., Mitra, A., Cultrera, J.J., Davarie, M., et al. (2014) Universal Marker and Detection Tool for Human Sarcoma Circulating Tumor Cells. Cancer Research, 74, 1645-1650. https://doi.org/10.1158/0008-5472.CAN-13-1739

[22] Fleischhacker, M. and Schmidt, B. (2007) Circulating Nucleic Acids (CNAs) and Cancer-A Survey. Biochimica et Biophysica Acta, 1775, 181-232.

[23] Stroun, M., Anker, P., Maurice, P., Lyautey, J., Lederrey, C. and Beljansky, M. (1989) Neoplastic Characteristics of the DNA Found in the Plasma of Cancer Patients. Oncology, 46, 318-322. https://doi.org/10.1159/000226740

[24] Thierry, A.R., Messaoudi, E.I., Gahan, P.B., Anker, P. and Stroun, M. (2016) Origins, Structures and Functions of Circulating DNA in Oncology. Cancer and Metastasis Reviews, 35, 347-376. https://doi.org/10.1007/s10555-016-9629-X

[25] Gahan, P.B. and Stroun, M. (2010) The Virtosome-A Novel Cytosolic Informative Entity and Intercellular Messenger. Cell Biochemistry and Function, 28, 529-538. https://doi.org/10.1002/cbf.1690

[26] Mouliere, F. and Thierry, A.R. (2012) The Importance of Examining the Proportion of Circulating DNA Originating from Tumor, Microenvironment and Normal Cells in Colorectal Cancer Patients. Expert Opinion on Biological Therapy, 12, S209S215. https://doi.org/10.1517/14712598.2012.688023

[27] Rykova, E.Y., Morozkin, E.S., Ponomaryova, A.A., Loseva, E.M., Zaporozhchenko, I.A., Cherdyntseva, N.V. and Laktionov, P.P. (2012) Cell-Free and Cell-Bound Circulating Nucleic Acid Complexes: Mechanisms of Generation, Concentration and Content. Expert Opinion on Biological Therapy, 12, S141-S153. https://doi.org/10.1517/14712598.2012.673577

[28] Laktionov, P.P., Tamkovich, S.N., Rykova, E.Y., Bryzgunova, O.E., Starikov, A.V., 
Kuznetsova, N.P. and Vlassov, V.V. (2004) Cell-Surface-Bound Nucleic Acids: Free and Cell-Surface-Bound Nucleic Acids in Blood of Healthy Donors and Breast Cancer Patients. Annals of the New York Academy of Sciences, 1022, 221-227. https://doi.org/10.1196/annals.1318.034

[29] Fan, H.C., Blumenfeld, Y.J., Chitkara, U., Hudgins, L. and Quake, S.R. (2008) Noninvasive Diagnosis of Fetal Aneuploidy by Shotgun Sequencing DNA from Maternal Blood. Proceedings of the National Academy of Sciences of the United States of America, 105, 16266-16271. https://doi.org/10.1073/pnas.0808319105

[30] Lo, Y.M.D., Chan, K.C.A., Sun, H., Chen, E.Z., Jiang, P., Lun, F.M.F., Zheng, Y.W., Leung, T.Y., Lau, T.K., Cantor, C.R., et al. (2010) Maternal Plasma DNA Sequencing Reveals the Genome-Wide Genetic and Mutational Profile of the Fetus. Science Translational Medicine, 2, 61 ra91. https://doi.org/10.1126/scitranslmed.3001720

[31] Holdenrieder, S., Stieber, P., Chan, L.Y.S., Geiger, S., Kremer, A., Nagel, D. and Lo, Y.M.D. (2005) Cell-Free DNA in Serum and Plasma: Comparison of ELISA and Quantitative PCR. Clinical Chemistry, 51, 1544-1546. https://doi.org/10.1373/clinchem.2005.049320

[32] Wimberger, P., Roth, C., Pantel, K., Kasimir-Bauer, S., Kimmig, R. and Schwarzenbach, H. (2010) Impact of Platinum-Based Chemotherapy on Circulating Nucleic Acid Levels, Protease Activities in Blood and Disseminated Tumor Cells in Bone Marrow of Ovarian Cancer Patients. International Journal of Cancer, 128, 2572-2580. https://doi.org/10.1002/ijc.25602

[33] Snyder, M.W., Kircher, M., Hill, A.J., Daza, R.M. and Schendure, J. (2016) Cell-Free DNA Comprises an in Vivo Nucleosome Footprint That Informs Its Tissues-ofOrigin. Cell, 164, 57-68. https://doi.org/10.1016/j.cell.2015.11.050

[34] Bidard, F.C., Weigelr, B. and Reis-Filho, J.S. (2013) Going with the Flow: From Circulating Tumor Cells to DNA. Science Translational Medicine, 5, 207ps14. https://doi.org/10.1126/scitranslmed.3006305

[35] Chevillet, J.R., Kang, Q., Ruf, I.K., Briggs, H.A., Vojtech, L.N., Hughes, S.M. and Tewari, M. (2014) Quantitative and Stoichiometric Analysis of the microRNA Content of Exosomes. Proceedings of the National Academy of Sciences of the United States of America, 111, 14888-14893. https://doi.org/10.1073/pnas.1408301111

[36] De Jong, O.G., Van Balkom, B.W.M., Schiffelers, R.M., Bouten, C.V.C. and Verhaar, M.C. (2014) Extracellular Vesicles: Potential Roles in Regenerative Medicine. Frontiers in Immunology, 5, 608. https://doi.org/10.3389/fimmu.2014.00608

[37] Tetta, C., Ghigo, E., Silengo, L., Deregibus, M.C. and Camussi, G. (2013) Extracellular Vesicles as an Emerging Mechanism of Cell-to-Cell Communication. Endocrine, 44, 11-19. https://doi.org/10.1007/s12020-012-9839-0

[38] Thakur, B.K., Zhang, H., Becker, A., Matei, I., Huang, Y., Costa-Silva, B.K. and Lyden, D. (2014) Double-Stranded DNA in Exosomes: A Novel Biomarker in Cancer Detection. Cell Research, 24, 766-769. https://doi.org/10.1038/cr.2014.44

[39] Hohaus, S., Giachelia, M., Massini, G., Mansueto, G., Vannata, B., Bozzoli, V., Criscuolo, M., D’Alò, F., Martini, M., Larocca, L.M., Voso, M.T. and Leone, G. (2009) Cell-Free Circulating DNA in Hodgkin's and Non-Hodgkin's Lymphomas. Annals of Oncology, 20, 1408-1413. https://doi.org/10.1093/annonc/mdp006

[40] The International Non-Hodgkin's Lymphoma Prognostic Factors Project (1993) A Predictive Model for Aggressive Non-Hodgkin's Lymphoma. The New England Journal of Medicine, 329, 987-994. https://doi.org/10.1056/NEJM199309303291402

[41] Basso, K. and Dalla-Favera, R. (2011) Germinal Centres and B Cell Lymphomagenesis. Nature Reviews Inmunology, 15, 172-184.

https://doi.org/10.1038/nri3814 
[42] Camus, V., Sarafan-Vasseur, N., Bohers, E., Dubois, S., Mareschal, S., Bertrand, P., Viailly, P.J., Ruminy, P., Maingonnat, C., Lemasie, E., Stamatoullas, A., Picquenot, J.M., Cornic, M., Beaussire, L., Bastard, Ch., Frebourg, T., Tilly, H. and Jardin, F. (2016) Digital PCR for Quantification of Recurrent and Potentially Actionable Somatic Mutations in Cirsulating Free DNA from Patients with Diffuse Large B-Cell Lymphoma. Leukemia \& Lymphoma, 57, 2171-2179. https://doi.org/10.3109/10428194.2016.1139703

[43] Garcia, V., Garcia, J.M., Silva, J., Martin, P., Peña, C., Dominguez, G., Diaz, R., Herrera, M., Maximiano, C., Sabin, P., Rueda, A., Cruz, M.A., Rodriguez, J., Canales, M.A., Bonilla, F. and Provencio, M. (2009) Extracellular Tumor-Related mRNA in Plasma of Lymphoma Patients and Survival Implications. PLoS ONE, 4, e8173. https://doi.org/10.1371/journal.pone.0008173

[44] Roscheweski, M., Dunleavy, K., Pittaluga, S., Moorhead, M., Pepin, F., Kong, K., Shovlin, M., Jaffe, E.S., Staudt, L.M., Lai, C., Steinberg, S.M., Chen, C.C., Zheng, J., Willis, T.D., Faham, M. and Wilson, W.H. (2013) Circulating Tumour DNA and CT Monitoring in Patients with Untreated Diffuse Large B-Cell Lymphoma: A Correlative Biomarker Study. The Lancet Oncology, 16, 541-549. https://doi.org/10.1016/S1470-2045(15)70106-3

[45] Colocci, N., Glantz, M. and Recht, L. (2004) Prevention and Treatment of Central Nervous System Involvement by Non-Hodgkin's Lymphoma: A Review of the Literature. Seminars in Neurology, 24, 395-404. https://doi.org/10.1055/s-2004-861534

[46] Chamberlain, M.C. (2005) Neoplastic Meningitis. Journal of Clinical Oncology, 23, 3605-3613. https://doi.org/10.1200/JCO.2005.01.131

[47] Sancho, J.M., Morgades, M., Alonso, N., Deben, G., Fernández de Sevilla, A., Vazquez, L., et al., on Behalf of Investigators of QUIT Study (PETHEMA GELTAMO and GOTEL Groups) (2008) Prospective Study on the Practice of Central Nervous System Prophylaxis and Treatment in Non-Hodgkin's Lymphoma in Spain. Medicina Clínica (Barc), 131, 441-446. https://doi.org/10.1157/13126952

[48] Feugier, P., Virion, J.M., Tilly, H., Haioun, C., Marit, G., Macro, M., et al. (2004) Incidence and Risk Factors for Central Nervous System Occurrence in Elderly Patients with Diffuse Large-B-Cell Lymphoma: Influence of Rituximab. Annals of Oncology, 15, 129-133. https://doi.org/10.1093/annonc/mdh013

[49] Boehme, V., Schmitz, N., Zeynalova, S., Loeffler, M. and Pfreundschuh, M. (2009) CNS Events in Elderly Patients with Aggressive Lymphoma Treated with Modern Chemotherapy (CHOP-14) with or without Rituximab: An Analysis of Patients Treated in the RICOVER-60 Trial of the German High-Grade Non-Hodgkin Lymphoma Study Group (DSHNHL). Blood, 113, 3896-3902.

https://doi.org/10.1182/blood-2008-10-182253

[50] Villa, D., Connors, J.M., Shenkier, T.N., Gascoyne, R.D., Sehn, L.H. and Savage, K.J. (2010) Incidence and Risk Factors for Central Nervous System Relapse in Patients with Diffuse Large B-Cell Lymphoma: The Impact of the Addition of Rituximab to CHOP Chemotherapy. Annals of Oncology, 21, 1046-1052. https://doi.org/10.1093/annonc/mdp432

[51] Lemma, S.A., Pasanen, A.K., Haapasaari, K.M., Sippola, A., Sormunen, R., Soini, Y., Jantunen, E., Koivunen, P., Salokorpi, N., Bloiqu, R., Turpeenniemi-Hujanen, T. and Kuittinen, O. (2016) Similar Chemokine Receptor Profiles in Lymphomas with Central Nervous System Involvement-Possible Biomarkers for Patient Selection for Central Nervous System Prophylaxis, a Retrospective Study. European Journal of Haematology, 96, 492-501. https://doi.org/10.1111/ejh.12626

[52] Purhonen, A.K., Juutilainen, A., Vänskä, M., Lehtikangas, M., Lakkisto, P., Hämä- 
läinen, S., Koivula, I., Jantunen, E. and Pulkki, K. (2015) Human Plasma Cell-Free DNA as a Predictor of Infectious Complications of Neutropenic Fever in Hematological Patients. Infectious Diseases, 47, 255-259. https://doi.org/10.3109/00365548.2014.985711

[53] Machado, A.S., Da Silva, R., Maghaläres, M.C., et al. (2010) Ciculating Cell-Free and Epstein-Barr Virus DNA in Paediatric B-Non-Hodgkin Lymphomas. Leukemia \& Lymphoma, 51, 1020-1027. https://doi.org/10.3109/10428191003746331

[54] Mussolin, L., Pillon, M., d'Amore, E.S., et al. (2011) Minimal Disseminated Disease in High-Risk Burkitt's Lymphoma Identifies Patients with Different Prognosis. Journal of Clinical Oncology, 29, 1779-1784. https://doi.org/10.1200/JCO.2010.32.8161

[55] Mussolin, L., Bonvini, P., ALi-Tahar, K., et al. (2009) Kinetics of Humoral Response to ALK and Its Relationship with Minimal Residual Disease in Paediatric ALCL. Leukemia, 23, 400-402. https://doi.org/10.1038/leu.2008.184

[56] Ali-Tahar, K., Damm-Welk, C., Burkhardt, B., et al. (2010) Correlation of the Autoantibody Response to the ALK Oncoantigen in Peditaric Anaplastic Lymphoma Kinase-Positive Anaplastic Large Cell Lymphoma with Tumor Dissemination and Relapse Risk. Blood, 115, 3314-3319. https://doi.org/10.1182/blood-2009-11-251892

[57] Mussolin, L., Pillon, M., d'Amore, E.S., et al. (2005) Prevalence and Clinical Implications of Bone Marrow Involvement in Peditaric Anaplastic Large Cell Lymphoma. Leukemia, 19, 1643-1647. https://doi.org/10.1038/sj.leu.2403888

[58] Mussolin, L., Burnelli, R., Pillon, M., Carraro, E., Farruggia, P., Todesco, A., Muscarin, M. and Rosolen, A. (2013) Plasma Cell-Free DNA in Paediatric Lymphomas. Journal of Cancer, 4, 323-329. https://doi.org/10.7150/jca.6226

[59] Mouliere, F., El Messaoudi, S., Pang, D., Dritschilo, A. and Thierry, A.R. (2014) Multi-Marker Analysis of Circulating Cell-Free DNA toward Personalized Medicine for Colorectal Cancer. Molecular Oncology, 8, 927-941. https://doi.org/10.1016/j.molonc.2014.02.005

[60] Kuppers, R., Klein, U., Hansmann, M.L. and Rajewsky, K. (1999) Cellular Origin of Human B-Cell Lymphomas. The New England Journal of Medicine, 341, 1520 1529. https://doi.org/10.1056/NEJM199911113412007

[61] Stevenson, F.K., Sahota, S.S., Ottensmeier, C.H., Zhu, D., Forconi, F. and Hamblin, T.J. (2001) The Occurrence and Significance of V Gene Mutations in B Cell-Derived Human Malignancy. Advances in Cancer Research, 83, 81-116.

[62] Kutz, D.M. (2015) Noninvasive Monitoring of DLBCL by Immunoglobulin HighThroughput Sequencing. Blood, 125, 3679-3687. https://doi.org/10.1182/blood-2015-03-635169

[63] Rossi, D., Diop, F., Spaccarotella, E., Monti, S., Zanni, M., Rasi, S., Deambrogi, C., Spina, V., Bruscaggin, A., Favini, Ch., Serra, R., Rampni, A., Baldorini, R., Foa, R. and Gaidano, G. (2017) Diffuse Large B-Cell Lymphoma Genotyping on the Liquid Biopsy. Blood, published online. https://doi.org/10.1182/blood-2016-05-719641

[64] Alizadeh, A.A., Eisen, M.B., Davis, R.E., Ma, C., Lossos, I.S., Rosenwald, A., Boldrick, J.C., Sabet, H., Tran, T., Yu, X., Powell, J.I., Yang, L., Marti, G.E., Moore, T., Hudson Jr., J., Lu, L., Lewis, D.B., Tibshirani, R., Sherlock, G., Chan, W.C., Greiner, T.C., Weisenburger, D.D., Armitage, J.D., Wamke, R., Levy, R., Wilson, W., Grever, M.R., Byrd, J.C., Botstein, D., Brown, P.O. and Staudt, L.M. (2000) Distinct Types of Diffuse Large B-Cell Lymphoma Identified by Gene Expression Profiling. Nature, 403, 503-511. https://doi.org/10.1038/35000501

[65] Bohers, E., Vially, P.J., Dubois, S., Bertrand, P., Maingonnat, C., Mareschal, S., Ruminy, P., Picquenot, J.M., Bastard, Ch., Desmots, F., Fest, T., Leroy, K., Tilly, H. and 
Jardin, F. (2015) Somatic Mutations of Cell-Free Circulating DNA Detected by Next-Generation Sequencing Reflect the Genetic Changes in Both Germinal Center B-Cell-Like and Activated B-Cell-Like Diffuse Large B-Cell Lymphomas at the Time of Diagnosis. Haematologica, 100, e280-e284. https://doi.org/10.3324/haematol.2015.123612

[66] Armand, P., Oki, Y., Neuberg, D.S., et al. (2013) Detection of Circulating Tumour DNA in Patients with Aggressive B-Cell Non-Hodgkin Lymphoma. British Journal of Haematology, 163, 123-126. https://doi.org/10.1111/bjh.12439

[67] Faham, M., Zheng, J., Moorhead, M., et al. (2012) Deep-Sequencing Approach for Minimal Residual Disease Detection in Acuate Lymphoblastic Leukemia. Blood, 120, 5173-5180. https://doi.org/10.1182/blood-2012-07-444042

[68] Logan, A.C., Zhang, B., Narasimhan, B., et al. (2013) Minimal Residual Disease Quantification Using Consensus Primers and High-Throughput IGH Sequencing Predicts Post-Transplant Relapse in Chronic Lymphocytic Leukemia. Leukemia, 27, 1659-1665. https://doi.org/10.1038/leu.2013.52

[69] Martinez-Lopez, J., Narasimhan, B., et al. (2014) Prognostic Value of Deep Sequencing Method for Minimal Residual Disease Detection in Multiple Mieloma. Blood, 123, 3073-3079. https://doi.org/10.1182/blood-2014-01-550020

[70] Mancuso, P., Calleri, A., Antoniotti, P., Quarna, J., Prumeri, G. and Bertolini, F. (2010) If It Is in the Marrow, Is It Also in the Blood? An Analysis of 1000 Paired Samples from Patients with B-Cell Non-Hodgkin Lymphoma. BMC Cancer, 10, 644. https://doi.org/10.1186/1471-2407-10-644

[71] Kristensen, L.S., Hansen, J.W., Kristensen, S.S., Tholstrup, D., Harsløf, L.B., Pedersen, O.B., De Nully Brown, P. and Grønbæk, K. (2016) Aberrant Methylation of Cell-Free Circulating DNA in Plasma Predicts Poor Outcome in Diffuse Large B Cell Lymphoma. Clinical Epigenetics, 8, 95. https://doi.org/10.1186/s13148-016-0261-y

[72] Favier, O., Heutte, N., Stamatoullas-Bastard, A., Carde, P., Van't Veer, M.B., Aleman, B.M., Noordijk, E.M., Thomas, J., Fermé, C. and Henry-Amar, M. (2009) European Organization for Research and Treatment of Cancer (EORTC) Lymphoma Group and the Groupe d'Etudes des Lymphomes de l'Adulte (GELA). Survival after Hodgkin Lymphoma: Causes of Death and Excess Mortality in Patients Treated in 8 Consecutive Trials. Cancer, 115, 1680-1691. https://doi.org/10.1002/cncr.24178

[73] Younes, A., Bartlett, N.L., Leonard, J.P., Kennedy, D.A., Lynch, C.M., Sivers, E.L. and Forero-Torres, A. (2010) Brentuximab Vedotin (SGN-35) for Relapsed CD30Positive Lymphomas. The New England Journal of Medicine, 363, 1812-1821. https://doi.org/10.1056/NEJMoa1002965

[74] Minich, S.S. (2012) Brentuximab Vedotin: A New Age in the Treatment of Hodgkin Lymphoma and Anaplastic Large Cell Lymphoma. Annals of Pharmacotherapy, 46, 377-383. https://doi.org/10.1345/aph.1Q680

[75] Camus, V., Stamatoullas, A., Mareschal, S., Viailly, P.J., Srafan-Vasseur, N., Bohers, E., Dubois, S., Picquenot, J.M., Ruminy, P., Maingonnat, C., Bertrand, P., Comic, M., Tallon-Simon, V., Becker, S., Veresezan, L., Frebour, T., Vera, P., Bastard, P., Tilly, H. and Jardin, F. (2016) Detection and Prognostic Value of Recurrent Exportin 1 Mutations in Tumor and Cell-Free Circulating DNA of Patients with Classical Hodgkin Lymphoma. Haematologica, 101, 1094-1101. https://doi.org/10.3324/haematol.2016.145102

[76] Jones, K., Nourse, J.P., Keane, C., Bhatnagar, A. and Gandhi, M.K. (2013) Plasma MicroRNA Are Disease Response Biomarkers in Classical Hodgkin Lymphoma. Predictive Biomarkers and Personalized Medicine, 20, 253-264. 
[77] Van Eijndhoven, M.A.J., Zijlstra, J.M., Groenewegen, N.J., Drees, E.E.E., van Niele, S., Rubina Baglio, D., van der Voorn, H., Libregts, S.F.W.M., Wauben, M.H.M., de Menezes, R.X., van Weering, J.R.T., Nieuwland, R., Visser, L., van den Berg, A., de Jong, D. and Michiel Pegtel, D. (2016) Plasma Vesicle miRNAs for Therapy Response Monitoring in Hodgkin Lymphoma Patients. JCI Insight, 1, e89631. https://doi.org/10.1172/jci.insight.89631

[78] Primerano, S., Burnelli, R., Carraro, E., Pillon, M., Elia, C., Farruggia, P., Sala, A., Vinti, L., Buffardi, S., Basso, G., Mascarin, M. and Mussolin, L. (2016) Kinetics of Circulating Plasma Cell-Free DNA in Paediatric Classical Hodgkin Lymphoma. Journal of Cancer, 7, 364-366. https://doi.org/10.7150/jca.13593

[79] Calvano, A., La Rocca, F., Simeon, V., Girasole, M., Dinarelli, S., Laurenzana, I., De Stradis, A., De Luca, L., Trino, S., Traficante, A., D’Arena, G., Mansueto, G., Villani, O., Pietrantuono, G., Laurenti, L., Del Vecchio, L. and Musto, P. (2017) MicroRNA-155 in Serum-Derived Extracellular Vesicles as a Potential Biomarker for Hematological Malignancies-A Short Report. Cellular Oncology, 40, 97-103. https://doi.org/10.1007/s13402-016-0300-x

[80] Vasioukhin, V., Anker, P., Maurice, P., Lyautey, J., Lederrey, C. and Stroun, M. (1994) Point Mutations of the N-Ras Gene in the Blood Plasma of Patients with Myelodisplastic Síndrome Ora Cute Myelogenous Leukaemia. British Journal of Haematology, 86, 774-779. https://doi.org/10.1111/j.1365-2141.1994.tb04828.x

[81] Koutova, L., Sterbova, M., Pazourkova, E., Pospisilova, S., Svobodova, I., Horinek, A., Lysak, D. and Korabecna, M. (2015) The Impact of Standard Chemotherapy on miRNA Signature in Plasma in AML Patients. Leukemia Research, 39, 1389-1395. https://doi.org/10.1016/j.leukres.2015.08.009

[82] Mithraprabhu, S., Khong, T., Ramachandran, M., Chow, A., Klarica, D., Mai, L., Walsh, S., Broemeling, D., Marziali, A., Wiggin, A., Hocking, J., Kalff, A., Durie, B. and Spencer, A. (2017) Circulating Tumour DNA Analysis Demonstrates Spatial Mutational Heterogeneity That Coincides with Disease Relapse in Myeloma. Leukemia, Epub ahead of print. https://doi.org/10.1038/leu.2016.366

[83] Oberle, A., Brandt, A., Voigtiaender, M., Thiele, B., Radioff, J., Schulenkorf, A., Alawi, M., März, M., Ford, C.T., Krohn-Grimberghe, A. and Binder, M. (2017) Monitoring Multiple Myeloma by Next-Generatin Sequencing of V(D)J Rearrangements from Circulating Myeloma Cells and Cell-Free Myeloma DNA. Hematologica, Epub ahead of print. https://doi.org/10.3324/haematol.2016.161414

[84] Isin, M., Ozqur, E., Cetin, G., Erten, N., Aktan, M., Gezer, U. and Dalay, N. (2014) Investigation of Circulating lncRNAs in B-Cell Neoplasms. Clinica Chimica Acta, 431, 255-259. 
Submit or recommend next manuscript to SCIRP and we will provide best service for you:

Accepting pre-submission inquiries through Email, Facebook, LinkedIn, Twitter, etc. A wide selection of journals (inclusive of 9 subjects, more than 200 journals)

Providing 24-hour high-quality service

User-friendly online submission system

Fair and swift peer-review system

Efficient typesetting and proofreading procedure

Display of the result of downloads and visits, as well as the number of cited articles Maximum dissemination of your research work

Submit your manuscript at: http://papersubmission.scirp.org/

Or contact jet@scirp.org 